tion indeed requires to be attacked with far more energy, vision and urgency than is apparent in recent references to it in reports from the Advisory Council. There is indeed much to be done to prepare the way for the difficult decisions that cannot long be postponed regarding the balance of research effort, both fundamental and applied, in Britain; and the deployment of our trained man-power in defence, industry, teaching and elsewhere, and the measures to be taken to ensure that the supply is adequate in quality and in numbers. The National Science Foundation's report, although prepared mainly for American readers, indicates numerous points calling for fresh thought and even inquiry in Britain, and it is to be hoped that it will be carefully studied by the Minister for Science and his advisors, the Parliamentary and Scientific Committee and professional associations of scientists and technologists, who are able to assist in forming that intelligent public opinion required to sustain public policy.

\section{APPLIED RADIATION CHEMISTRY}

\section{Chemische Reaktionen lonisierender Strahlen (Radiation Chemistry)}

Herausgegeben von Prof. Hermann Mohler. Pp. 299. (Aarau und Frankfurt am Main: Verlag H. R. Sauerländer und Co., 1958.) 30.80 D.M.

A SIGNIFICANT diminution in the cost of atomic power could be achieved if the energy at present 'lost' as radiation were used to achieve large-scale chemical production or processing. In many countries, private and government laboratories exist to explore the possibilities of applied radiation chemistry, and already a number of processes have been, or are being, used commercially. Hitherto the use of radiation in the chemical industry has been very small, primarily because radiation merely generates in chemical systems reactive species such as ions and/ or free radicals which in most cases can be produced in a more controlled manner by more conventional chemical means. This fact and certain inherent disadvantages in the use of radiation are likely to limit its successful application to fields where chemical methods are either non-existent or very difficult to apply. The book under review has been written in the belief that the time has now come when the chemical technologist should know something of the principles and applications of radiation chemistry.

The book originated in a course of lectures in the University of Basle in 1956, and some of the authors contributing to this book took part as lecturers. After a brief definition of the subject, the first half of the book is concerned with a discussion of the necessary background knowledge of radioactivity, followed by an account of radiation sources (parts of which read like a technical sales brochure) and dosimetry, with a minor chemical digression (pages 54-68) in which a sketchy account of some radiation chemical mechanisms is given. The latter part of the book deals with the interaction of radiation and matter and presents somewhat cursory accounts of selected radiation-induced reactions in solid, liquid and gaseous phases, and concludes with two chapters, rather surprisingly in English, entitled "The Effects of Atomic Radiation on Polymers" and "Radiationinduced Reactions of Potential Industrial Importance".

The book displays several of the disadvantages of composite authorship. For example, in the whole of the last chapter the phrase 'radiochemical reaction' is given a meaning quite different from that commonly accepted and from that carefully specified by the editor and writer of the introduction. Again, there is a great unevenness in level of treatment; the chapter on polymers, though by an expert, is almost at the level of popular science exposition, whereas that on dosimetry is a good deal more profound. These defects are minor in comparison with several distorted and often erroneous notions about radiation chemistry which the book contains. The stated origin of the hydroxyl radicals in irradiated water (p. 63), the mechanism of formation of $\mathrm{H}_{3} \mathrm{O}^{+}$on electron impact on water vapour (Table $4.08, p .194$ ), and the mechanism of the reduction of ceric ions (p. 152), all contain inexcusable errors which are not printing slips. The complete omission of ion-molecule reactions and the inadequate treatment of the competition between diffusion and combination of radicals, both matters of central importance, are serious deficiencies. When one reads phrases such as the following about the oxidation of sulphur dioxide by oxygen in aqueous solution, "Attention will have to be given to the effect of trace metals, for example, iron and copper, on the reaction" (p. 251), or "There is no published information to indicate to what extent chain reactions play a part:" (p. 249), one marvels how the author of this chapter can have overlooked the classical works of Bäckström and others. Any chemist or chemical technologist using the Fricke dosimeter to determine doses or dose-rate who uses the $G$ values for this system given on pages 156 and 161 must be content with values which will be $6-7$ per cent too high.

Apart from the dropping of an ' $h$ ' from Shrivenham, the book is well printed and produced.

F. S. Dainton

\section{THE THEORY OF DAMS}

\section{The Theory of Storage}

By Prof. P. A. P. Moran. (Methuen's Monographs on Applied Probability and Statistics.) Pp. 111. (London: Methuen and Co., Ltd.; New York: John Wiley and Sons, Inc., 1959.) 13s. $6 d$. net.

ANY of the individual problems of applied 1 probability have a very respectable antiquity; thus queueing theory began with Erlang in 1908, what we now call birth-and-death processes were first studied by Galton and Watson in 1873, and the use of probabilistic models in physics and astronomy can be traced back to much earlier dates than these. But it was not (in Great Britain at least) until just after the Second World War that the full range of possibilities was widely recognized; during the past fifteen years the subject of applied probability has grown to such an extent that it now rivals in importance its elder sister, the statistics of experimentation. That the publishers of this new series of monographs recognize this fact is clearly shown by the general title which they have given to the series, by the individual titles of the five volumes so far announced (only one of these is concerned with statistics as ordinarily 